\title{
'Starring... Dyer?’: Re-visiting Star Studies and Contemporary Celebrity Culture
}

\section{Su Holmes \\ University of Kent}

Keywords: Celebrity, fame, stardom, Richard Dyer, selfhood, celebrity theory

\begin{abstract}
Responding to the apparently ubiquitous interest in contemporary fame, the last ten years has seen an expansion of academic work on stardom/celebrity, whether in film, media and cultural studies or beyond. Reflecting contemporary popular discourse, the emphasis here has often been on change: the notion that modern celebrity represents a qualitative break with the past. But what has arguably been lacking is a sense of dialogue or debate about the implications of this 'shift' for (now long-standing) theoretical/methodological approaches in the field. In this article, I bring aspects of these spheres together - the history of academic discourse on celebrity and the province of modern fame - in order to stimulate questions about their present and future relationship. In particular, I return to the seminal work of Richard Dyer (1979; 1986) as a form of dialogue between these spheres, placing his intervention within the history of work on stardom/ celebrity, and evaluating its relationship with contemporary celebrity culture.
\end{abstract}

\section{Introduction}

In early 2005 I was approached by an independent television company undertaking research for a documentary about 'ordinary' people on television. Prompted by the contemporary proliferation of reality TV, they were particularly interested in the relationship between television, 'ordinary' people and fame. Aware of the burgeoning academic interest in reality TV, the company were looking for academics to comment on this phenomenon. In making my own bid for media 'fame', I began a number of exchanges with the researcher. A few days prior to the shoot, we entered into a mock phone interview, and I was asked such questions as what prompts 'ordinary' people to seek fame on television, when they appear to lack the traditional resources of 'talent'? Why are we fascinated by such people? From the start, I am unwilling to suggest that these are seismic shifts in fame, all suddenly emerging since the late 1990s.

Westminster Papers in Communication and Culture (C) 2005 (University of Westminster, London), Vol. 2(2): 6-21. ISSN 1744-6708 (Print); 1744-6716 (Online) 
After this, the conversation seems slow, and is punctuated by awkward silences. When I suggest that there may be connections with the construction of fame from over fifty years ago, things go from bad to worse. (Notorious UK Big Brother contestant Jade Goody is mentioned repeatedly here, and there is the persistent attempt to solicit a response in which she appears as a new form of celebrity, the epitome of an age where fame has opened its door to all.) More awkward silences follow, and the conversation ends a few minutes later. The next day I receive an email from the researcher saying that the shoot has been cancelled, and that the company will ring to re-arrange. The next time I hear about the documentary (I'll Do Anything To Get On TV (C4, 10 April, 2005)) I am watching it on television.

I begin with this example as it illustrates the contemporary cultural appetite for producing self-conscious narratives about the development and status of modern fame. We inhabit an age which is remarkably vocal about the phenomenon of celebrity, and the current watchword in media commentary appears to be change the prevalent sense that modern celebrity represents a qualitative break with the past. Such claims about modern fame are often made with very broad strokes, but they have made a successful bid for cultural legitimacy and acceptance. The example above might simply point to the desire of the television documentary to avoid being 'too academic' (my comments at least complicated the production of smooth 'sound-bite' argument), but it also exemplifies how it has become unfashionable to question - or even qualify - this popular cultural narrative about fame. But what interests me here is that there has been an ambivalence about how academia has responded to these debates about change and development in celebrity culture.

In terms of an interest in celebrity, it may appear that media commentary and academic discourse occupy separate spheres (as my difficulty with the documentary might attest). But academic discourse is always part of the cacophony of voices commenting on fame in any one moment. Indeed, 'academic' texts such as those by Daniel Boorstin (1961) and Leo Lowenthal (1961), are now read as elucidating aspects of the history of fame - the discourses in operation during the time in which they were writing. In fifty years time, the same might be said of our work today. In this article, I want to bring aspects of these spheres together - the history of academic discourse on celebrity and the province of modern fame - in order to stimulate questions about their present and future relationship. In particular, and for reasons that I explore below, I want to return to the work of Richard Dyer $(1979 ; 1986)$ as a form of dialogue between these spheres. I begin by mapping out the parameters of Dyer's intervention, before moving on to examine the challenges to his position - whether these have arisen from theoretical/ methodological shifts within academia, or more 'external' shifts in the nature of fame. In the last section of the article, I evaluate these debates by exploring the 
relationship between Dyer's work and contemporary media contexts, primarily in relation to the UK celebrity magazine heat and reality TV.

\section{All Change?}

We have recently entered something of a boom period in the academic analyses of celebrity. P. David Marshall has described how, particularly when we survey the last decade, it is clear that the 'academy has embraced the study of celebrity and fame' (2004). It may thus seem difficult to reconcile this with Bruce Babington's suggestion (in introducing the film collection British Stars and Stardom) that 'it is hard to feel swamped by significant textual commentary on stars...' $(2001,23)$. The way the field is described in each case, first as a phenomenon and broader social process, and second as focusing on individual 'stars', may well point to the fact that much of this expansion has occurred outside of film studies - in the domain of media, cultural and also literary studies (Gamson 1994, Marshall 1997, Rojek 2001, Moran 2000). Moving across a range of cultural domains - from reality TV, literature, the internet, popular music to politics - this has drawn upon a wider range of disciplinary and methodological approaches (see Barker 2003). But the disjuncture between these spheres might equally point to an absence of dialogue about the changing analytic trajectory of the field. This is something which is as important as, and intrinsically related to, claims about the changing trajectory of modern fame.

Here, I want to focus this reflection around the work of Richard Dyer (1979; 1986). Although critical study of stars and stardom did not commence with Stars (Barker 2003, 5), it undoubtedly had a seminal influence on the field, and continues to be a canonical text in this respect. In Stars (1979), Dyer posed new questions about stardom, particularly in inviting analyses of stars in the realm of representation and ideology (Barker 2003, 6). Dyer focused in particular on the relationship between stardom, star images and discourses of individualism. Although discussed in more detail below, Paul McDonald, for example, summarised Dyer's approach as the investigation of how 'cinema circulates the images of individual film performers and how those images may influence the ways in which we think of the identity of ourselves and others' $(1998,176)$. In drawing attention to new ways of conceptualising and researching a star 'image' (the most famous example here being Marilyn Monroe) (Dyer 1986), Dyer later proffered seminal methodological tools for the analysis of stardom - a model for mining the cultural significance of a star by examining the network of ideological discourses from which they emerged. 
In both research and teaching on the subject, this approach still remains important, particularly in film studies. Yet there have clearly been changes in the field, both in relation to perceived shifts in the nature of fame, and changing critical, theoretical and methodological fashions. Within film studies, for example, there has been a move toward a greater emphasis on various spheres such as political economy, screen acting/performance, and empirical audience research - all of which were seen to be marginalised in Dyer's earlier work (McDonald 1998; Barker 2003). Within film studies and beyond, there has also been a greater emphasis on the history of stardom, not simply in terms of its origins and evolution, but the impact of changing technological and media contexts (ranging from the advent of sound, television, the Internet to digital technologies). In Stars, Dyer's main focus was the Classical Hollywood period of cinema, and questions have always been raised about the development of film stardom, and wider media celebrity, after this time. In the contemporary media landscape, the contexts of stardom are less specific, blurring the boundaries of terms used to conceptualise fame (Geraghty 2000). For example, Deborah Jermyn has commented that, in the pages of contemporary celebrity magazines:

The hierarchy once headed by cinematic stars has apparently shifted as glamorous names from film, TV and other arenas feature alongside one another as equal objects of desire and public interest. They are all as likely as one another to appear as designer muses and devotees, a shift which has been central in discourses bemoaning the 'decline' of contemporary celebrity. (forthcoming 2006)

Indeed, surveying this shift, Barker acknowledges that it has undermined the 'exclusivity' of cinematic stardom $(2003,11)$, but it is notable that in his account, 'celebrity' studies is something that happens 'over there', beyond the still perceptible boundaries of film 'stardom'. What this points to is something of a crisis in terminology when it comes to discussing fame in the contemporary media landscape. In star studies, the term 'stardom' was conferred to denote a dialectic between on/off-screen presence (Ellis 1982). In comparison, the term 'celebrity' has had an ambiguous popular and academic circulation - one that has long since been structured by discourses of cultural value (Marshall 1997). It is variously used to indicate a more fleeting conception of fame (Rojek 2001, 9), the contemporary state of 'being famous' in which 'meaningful' distinctions and hierarchies have diminished, or when fame rests predominantly on the private life of the person, as opposed to their performing presence (Geraghty 2000, 187). Yet it is worth noting here that contemporary celebrity texts rarely respect these conceptual divisions. Certainly in heat magazine, names ranging from Julia Roberts, J-Lo, Jude Law, Camilla Parker-Bowles, Jade Goody to Ant n' Dec, variously appear as 'stars', 'idols' and 'celebs'. This might simply be evidence of heat's 'boisterously democratic approach' (Holmes 2005, 24) to the famous, and for some, further 
evidence of a culture in which 'meaningful distinctions' in fame have declined. But it has already been established that, in studying the phenomenon of celebrity and fame at any one moment, we are essentially studying traces of how it is written about, whether we are talking about celebrity producers, journalists or academics. Such texts, then, are no less resources for the study of this trajectory, nor less constitutive of its social meanings.

The emphasis on the political economy of fame has been seen elsewhere (e.g. Turner et al 2000; Turner 2004), and represents part of the expansion of the field in media and cultural studies. With less of an historical attachment to textual analysis, particularly when compared to film studies, it is perhaps no surprise that the emphasis here has increasingly been on celebrity as a phenomenon - on the apparatus or system, the processes of fame, rather than the reading of individual images per se (although this has certainly been a visible current of research). As Turner notes, a common approach here is to emphasise that celebrity is not a property of specific individuals. Rather, it is constituted discursively, by the way in which the individual is represented' (Turner et al. 2000, 11). 'Celebrity', then, is here conceived in terms of the system of representation - its conventions, structures and circulation - within which the celebrity self resonates within the public sphere. However, while there is the sense in which this is presented as a 'recent' conceptual shift (e.g. Turner 2004, 7), this was surely integral to Dyer's (1979; 1986) own intertextual approach to stardom. His focus was not simply the reading of a particular star image, but also an analysis of the common discursive structures through which stars were circulated. For example, an obvious reference point here is his conception of the 'ordinary/extraordinary' paradox, the notion that stars are constructed as being 'ordinary' (like 'us'), yet simultaneously distinctive and 'special'. Either way, with the emphasis increasingly on the 'discursive regime' through which celebrity is produced and consumed, it is not that media distinctions are rendered redundant, but rather that different taxonomies of fame have also emerged (Turner 2004, 22). Chris Rojek (2001) for example, has categorised fame in relation to why the 'celebrification' process occurs. $\mathrm{He}$ suggests distinctions between 'ascribed' celebrity (a product of lineage), 'achieved' celebrity (a meritocratic conception where fame is linked to talent and accomplishment), and 'attributed' celebrity (which simply emerges from 'concentrated' media representation) (Ibid, 17). The emphasis here is clearly that we have moved toward a culture of attributed celebrity. This is very much in keeping with the popular discussion of fame in the contemporary moment, and again underlines the reciprocal relationship between public and academic discourse. 


\section{'Ideological E-Numbers': A Retreat From 'Big Theory'?}

This is of course an interpretation of the field, and its development could be characterised in other ways. Yet a common theme, as Barker describes, might be conceived as move away from 'the "big theories" from which star studies began' $(2003,13)$. Barker takes a broad sweep here and refers to the earlier influence of different forms of Marxism in star studies, and essentially the entire premise that stars need to be explained ideologically (see also Lovell 2003). This shift is arguably related as much to the internal dynamics of film, media and cultural studies as to 'extrinsic' developments in fame (although we would of course hope that the former are refined to analyse the latter), speaking as it does to the broader questioning of 'grand' theories and paradigms. For example, emerging from a context less at ease with the powerful ideological coherence of the media text as advanced by earlier versions of Marxism, Barker suggests that the 'consumption' of stardom in Dyer's paradigm was akin to the ingestion of 'some distinctly unhealthy ideological E-numbers' (2003, 6). He then surveys the impact of Heavenly Bodies in its focus on the contextual construction of the star image, referencing the case study of Marilyn Monroe:

\footnotetext{
...Dyer claimed to reveal a really close 'fit' between her persona... and the ideological tensions of a period... Was [he]... just a touch fortuitous in finding such a neat fit? Was this a special case? If stars are more than just filmic figures, why is it not easier to locate other cases where stars may resolve ideological tensions? Or perhaps we have looked for too tidy relations between stars and ideological processes?... [Dyer's] study stands worryingly alone. (Ibid, 14-15)
}

First, more akin to a view of popular culture cultivated by the Frankfurt school, it is hard to develop the sense that stars should carry a health warning in Dyer's work - which seems to me to delicately balance our cultural fascination with stardom, while probing its wider social and cultural significance. Second, while the Monroe case study may have ultimately pointed toward ideological 'resolution', the ideological implications of Dyer's approach are clearly open to interpretation. While some describe his approach as heavily influenced by Althusserian Marxism (e.g. Lovell 2003, 260) (in which the crucial function of ideology was to make individuals misperceive themselves as subjects, implying a more limited role for audience agency), others position his work as having more of an affinity with Gramscian Marxism, in which stardom is an arena of negotiation between the star, the media and the audience. This seems quite clear in Marshall's elaboration of Dyer when he explains: 'In a form of working hegemony, the celebrity is configured' [my italics] (1997, 12). Either way, to describe the Monroe example as standing 'worryingly alone' is unconvincing. The impact of Dyer here should surely be seen as fostering the methodological approach for producing contextual readings of the star image - an approach which seems to have influenced nearly all such readings 
in film, media and cultural studies since. The conclusion regarding the (ideological) function of that image is less important than the method through which it is pursued. Dyer's reading of Monroe was undoubtedly more detailed and exhaustive than many that followed, but it spawned, as Jo Littler has described, a 'whole generation of film... students who wrote essays on the construction of a particular star's image and fame' $(2004,12)$. This is surely its primary legacy.

At the same time, there may well be external changes which beg questions about Dyer's approach. In a space crowded with so many faces for a shorter stretch of time, apparently placed there (as current wisdom would have it) by mere 'attribution', is the popularity of certain celebrities best explained by their deep, structural relationship with the ideological contexts of their time? The extraordinary outpouring of public grief which met the death of Princess Diana has also been analysed from the perspective that there was something significant about her relationship with prevailing discourses of the time - whether these are related to discourses of nation, gender, sexuality and beyond (e.g. Kear and Steinberg 1999). Equally, a star such as David Beckham, for example, has been studied in relation to his dramatization, and potential 'resolution', of discourses surrounding contemporary masculinity (Whannel 2001). But there are two crucial points to make here. First, given the more recent expansion of interest in global and transnational cultures, neither of these examples fit neatly into a framework focused on stars as representations of national ideologies and identity. The emphasis above was precisely on the global circulation of Diana, the construction of a 'global community of mourning' which was inflected in a multitude of different ways by discourses of nationhood, community and identity (see Kear and Steinberg 1999). A second criticism might be that these examples tend more toward the exceptional than the typical. Would we apply this same approach to the names we fleetingly recognize in the crowded pages of celebrity magazines? This in itself draws attention to the manner in which, as Turner has described, there are 'many forms and sites' of celebrity consumption' in which the 'mode of engagement... can vary dramatically' $(2004,108)$. Visiting a celebrity porn site, reading a celebrity magazine, going to the cinema or attending a pop concert, all suggest different relations with, and investments in, celebrity culture (Ibid). From this perspective, attributing a cultural function to the process may indeed be problematic. ${ }^{1}$

However, if conceived in general terms, it is difficult to see why we would want to uncouple the conceptual link between the popularity of a celebrity and the suggestion that they work over 'useful' questions within the social and cultural contexts of their time. Dyer's main thesis here was that, rather than simply some 'special', 'magic' quality of the individual, a star's 'charisma' is a product of the ways in which their image engages social issues and dilemmas (McDonald 1998). 
A celebrity does not need to command the same kind of global appeal and apparent (image) longevity as Princess Diana or David Beckham in order to function in this way. For example, model 'Jordan' (aka Katie Price) appeared in the third series of ITV1's reality show I'm a Celebrity... Get Me Out of Here! (2004). Primarily famous for the enormous size of her surgically enhanced breasts, Jordan is often invoked as the epitome of the worthless nature of contemporary celebrity (and is undoubtedly perceived as 'famous for being famous'). In appearing in the programme, she attracted the majority of media attention, not least of all because of her flirtatious on-screen 'romance' with Australian singer Peter Andre. Popular magazines, as well as daytime television shows (e.g. This Morning, Richard and Judy), entered into debate - as is common in coverage of reality programmes - as to the nature of her 'true self ('Jordan' or the apparently less glamorous 'Katie Price'). But this comparison often adopted a specifically gendered inflection. One strand of debate, for example, engaged discussion of her perceived status as either 'Selfmade businesswoman' or 'brainless bimbo'. Indeed, on Richard and Judy, viewers were invited to ring in to register their opinion in a phone poll (10 February, 2004). This was followed by coverage of real female business entrepreneurs discussing the problems they faced negotiating a 'man's world' - particularly in terms of how the valuing of femininity as appearance impacted upon this. Although the most obvious question here might be why Jordan must be conceived as 'businesswoman' or 'bimbo' (brains or looks), this case study would not look out of place in recent discussions about the media construction of post-feminism (Tasker and Negra 2005). Indeed, if conceived as playing out tensions surrounding women's contemporary gender/economic 'power', it is interesting that the initial media emphasis was on Peter 'taming' the sexually provocative Jordan, and falling in love with 'Katie', the willing-to-be-domesticated 'girl' beneath (see Holmes, forthcoming, 2006). While I don't want to push this case study too far, it demonstrates precisely a celebrity dramatising contemporary social discourses of the time, and thus having a 'useful' discursive function in this respect. ${ }^{2}$

\section{Locating The 'Self': The Search Goes On....}

There are certainly wider issues to probe here given the centrality of this approach in Dyer's work, but in the remainder of this article I want to focus on one of the most important arguments of Stars - and the one which seems most pertinent to debates about change in modern celebrity. Given that fame has often been traced in relation to Western ideals of individualism (Dyer 1979; Marshall 1997; see also Coelho in this issue), it has been perceived as intimately intertwined with the construction of social and cultural identity. As indicated at the start, in terms of his bid to ask questions about the social and ideological function of stars, a crucial element of Dyer's work was to explore how stars articulated ideas about personhood. Dyer argued that 'stars articulate what it is to be human in society: 
that is, they express the particular notion that we hold of the "individual" (1986, 8). Supporting the notion of individualism upon which capitalist society depends, Dyer suggested that the continual attempt to negotiate 'authenticity' in the star image, the perpetual attempt to lay claim to the 'real self' (what is the star 'really like?'), was organised around a desire to suggest a 'separable, coherent quality, located "inside" consciousness and variously termed "the self", "the soul", "the subject"...' (Dyer 1986, 9).

However, post-structuralist and postmodern strands of thought have undermined and critiqued the very concept of identity and clearly made a 'depth' model of the self unfashionable. In what is part of a larger questioning of Dyer's emphasis on the relationship between stardom and ideological resolution, Alan Lovell has challenged the very origins of his model by arguing that 'stars are improbable candidates for carrying out the ideological task [Dyer] assigned to them' (2003, 261). He argues that their notorious 'capriciousness' and superficiality represent the very antithesis to the concept of a unified, stable identity. 'In the popular imagination', Lovell suggests, 'stars are the polar opposite of the solid bourgeois citizen...' (Ibid). Second, Barry King's argument can be seen as an implicit challenge to Dyer's when he draws attention to the changed 'existential parameters of stardom... Today's stars ... epitomise the post-modern self, a decentered subject, deeply reflexive and disdainful of claims to identity' $(2003,45)$.

First, Lovell's point seems to be less an argument about development and change in star culture, than it objects to the validity of Dyer's original model. But if we take Lovell's point that stars are the 'polar opposite' of a coherent and stable identity, Dyer surely acknowledged this when he suggested that:

It is one of the ironies of the whole star phenomenon that all these assertions of the reality of the inner-self... take place in one of the aspects of modern life that is most associated with the invasion and destruction of the inner self and the corruptibility of public life, namely the mass media [my italics]. $(1986,15)$

It takes as given that there is performance, construction and mediation, as this is what prompts such self-conscious debates about the status of the self. In short, it was because of the apparatus of manipulation and 'hype' that stars could operate as a site for the working through of discourses on the construction of identity. (In this respect, while Turner is right that modes and sites of engagement with celebrity can differ significantly, they are often all linked by this negotiation of 'authenticity'). If we were to apply the questions we ask of celebrities to the broader context of human identity, they explore 'useful' issues surrounding selfhood: is there a distinction between our 'private' and 'public' selves? Do we 
have any 'unique' essential, 'inner' self, or are we simply a site of self-performance and public presentation? In this respect, Dyer pointed not only to the shoring up of the concept of the individual, but also the ways in which stars work through its anxieties, articulating both the promise and the difficulties of its status. The way in which this occurs may change over time (we might note the contemporary interest in plastic surgery where searching for the 'reality' of the celebrity self is concerned), but the questions asked above remain the same.

Second, in King's argument about a 'new configuration in the existential parameters of stardom' (2003, 45), he invokes Joshua Gamson's (1994) empirical audience research into the reading strategies used to approach contemporary celebrity. In this respect, Gamson found that these varied considerably, ranging from 'Traditionalists' or 'Believers' (who read the celebrity text as a realistic representation), 'Second-order Believers' (who acknowledge the highly constructed nature of the celebrity text but hold onto the belief that there will be access to 'the real'), to positions such as Game-players and Postmodernists (in which pleasure comes from the process of detection rather than the end result, or the bid to dwell on the inauthenticity of the field and revel in its 'visible play of images') (Ibid, 156). The fact that it may be possible to 'ride the belief/disbelief and fiction/reality axes... with no particular destination' (Ibid, 178) certainly poses questions about the negotiation of authenticity in the celebrity text, and concurrently, the framework of selfhood this implies.

Gamson's excellent historical research into what he calls changing 'explanations of fame' (the 'implicit and explicit implantation as to why people become famous'), also elucidates how such a perspective may be related to shifting constructions of celebrity. While, for example, in the Classical Hollywood period, the emphasis may no longer have been on 'greatness' or great 'genius', explanations of fame still peddled narratives pivoting on conceptions of a 'natural rise': 'Fame, based on an indefinable internal quality of the self was natural, almost predestined' (Ibid, 32). However, particularly since the post-war period with its de-centralisation of stardom and explosion of media outlets, the increasing visibility of the publicity machine itself began to pose a threat to such myths. From this perspective, 'the challenge from the manufacture-of-fame narrative has been greatly amplified... [ [] $\mathrm{t}$ has become a serious contender in explaining celebrity' (Ibid, 44). However, important in Gamson's argument is that by the late twentieth century, it was possible to discern strategies intended to cope with the increasing disjuncture between the narratives here (and the threat that the decline of the merited claim to fame discourse may pose to the capitalist enterprise of celebrity). In particular, he points toward the devices of the 'exposure' of the process, the construction of an ironic and mocking perspective on celebrity culture, and an increased emphasis on flattering the 'power' of the audience. In Gamson's argument, this can be read as 
aiming to keep the negotiation of authenticity intact. In inviting the audience to see 'behind' the image, or adopting an ironic perspective on the field, it may avoid the more 'disruptive notion that there is nothing behind a fabricated, performed image but layers of other fabricated, performed images' $(2001,276)$.

Indeed, while contemporary celebrity magazines such as heat and Now revel in an irreverent and often ironic attitude toward celebrity culture (or 'Celebville' as they call it), the continued negotiation of authenticity still sits at the very core of their framework. With their 'democratised' appetite for stripping away the 'façade', celebrities are relentlessly pursued doing mundane activities - loading up the car at a shopping centre, exiting a DIY store, or walking with their children or dogs in a park (Holmes, 2005). This 'democratised' attitude also extends (somewhat more aggressively) to sections such as ' $100 \%$ Unapproved' or 'Scandal', which delight in revealing celebrity sweat patches, spots, or ill-applied fake tans. These contexts are all represented through the rhetoric of candid photography, the blurred focus and grainy aesthetic of which not only trades on an aesthetic of realism, but also the belief in 'the higher truth of the stolen image [my italics]' (Sekula, cited in Becker 1993, 142). In terms of celebrity, this promises to manifest more of the inner being' when compared to the calculated pose, stance or expression (Ibid). The magazine certainly acknowledges the performative nature of the celebrity self criticising celebrities who seem to be 'posing' for candid shots, for example (e.g Victoria Beckham). But this is only to keep the 'authenticity' of the 'real' candid image intact and thus does not seem to challenge the emphasis on the 'negotiation of authenticity' in Dyer's work.

Reality TV also appears to conform to Gamson's paradigm. Reality-pop shows such as Pop Idol and X-Factor quite literally claim to invite us 'behind-the-scenes' of fame production (and combined with an emphasis on the power of the audience), this comprises the central narrative structure of these shows (see Holmes 2004b). Big Brother functions differently, but it still aims to show us celebrities-in-process given that, however important their credentials as 'ordinary' people are to the programme's claim to realism (Couldry 2002), they are in some sense celebrities from the moment they enter the house. But what many reality formats have in common is the discursive emphasis on locating the 'authentic', 'core' self - as understood in terms of public disclosure and the revelation of personal identity.

Particularly in Big Brother, we witness continual discussion of 'who is being themselves?', who is 'performing for the camera?' This is a crucial criterion in how the housemates judge and discuss one another, and as such, it functions to frame our own interpretive framework for the show. The spatial construction of the house, incorporating the 'privacy' of the diary room where observations about fellow contestants can be 'confided' in the audience, fosters this discussion. 
Furthermore, the post-eviction interviews in Big Brother positively solicit this speculation, specifically asking contestants to judge the sincerity of the selves put on display in the house, and asking the evictee if they were ever able to forget the cameras were rolling (and thus present themselves 'as they really are'). The answer to this is always 'yes'. To date, nobody has won the show (in the UK at least) for playing a 'good' game - for displaying open duplicity or machiavellian traits. ${ }^{3}$ Indeed, time and time again, however much the winners may vary, there is a pull toward validating those that (appear to) have been that 'true' to themselves. Certainly, such discussions contribute to the programme's self-conscious negotiation of the real, focusing as they do on exploring the difference between 'reality' and its production, as well as the 'real' and the performed self. In this respect, they make clear how the entire issue of re-presentation is explicitly put on the agenda by the programme itself, in ways which both assume, and flatter, the media literacy of the audience. But as Annette Hill has argued, capitalising on the tension between performance and authenticity, reality TV nevertheless solicits us "to look for the "moment of truth" in a highly constructed and controlled television environment' $(2002,234)$. That is, while it may adopt a self-reflexive approach to its representation of the real, neither the programmes nor the audience have rejected 'the idea of authenticity in factual entertainment', nor the selves which are put on display (Ibid, 336).

It is thus perhaps no surprise that, in terms of their celebrity construction in popular magazines, this discourse of 'authentic' selfhood remains prominent. In an interview with Brian Dowling, winner of the second UK Big Brother, heat magazine comments how: 'In just over 12 months he may have gone from Ryanair steward to bona fide celebrity, but he's still the same warm, irreverent and bitchy character who won Big Brother last summer' (21-27 September, 2003, 76). When asked if he had any advice for Kate Lawler, winner of the third series of the programme, Brian explains how: 'I just told her to be herself and not to change', to which heat approvingly replied, 'wise words indeed' (Ibid). Dowling is presented approvingly here because he appears 'unchanged' by fame, with the implication being that he is the same person on/off 'stage'. (Indeed, in offering us a trajectory where we 'know' the person from the start, reality TV in many ways aims to push for a coincidence between 'private' and 'public' personae, a discourse which is usually associated with more traditional myths of fame) (see Gamson 2001). This is what Dyer termed bearing 'witness to the continuousness of [the self]' and, returning us to the ideology of the self, the appearance of sincerity and authenticity are two qualities which have historically been 'greatly prized' in stars (Dyer 1979, 11).

Gamson's analysis provides a useful historical trajectory within which Dyer's arguments concerning selfhood can be further explored. Nevertheless, King's point above about changed 'existential parameters of stardom' (2003, 45) is still 
fundamentally a question about reception - how the celebrity text is read and consumed. While we might note that Gamson's research suggests a range of different responses in this respect, a problem here is that we do not have similar empirical audience research from the past. ${ }^{4}$ From this necessarily unbalanced perspective, it is surely much easier to insist that a sceptical approach to the celebrity self is intrinsically 'new'.

\section{Conclusion}

As any field expands, it is crucial to respond to apparent innovation not simply by developing 'new' theoretical and methodological approaches, but also by reconsidering the relevance and dynamics of existing models. In the context of star and celebrity studies, I have aimed to contribute to this process here, not least of all because this concept of revisitation and dialogue does not seem as explicit as we might expect. While Paul McDonald has foregrounded the importance of a diachronic approach to stardom - "what is different about "Monroe" in the 90s to Monroe in the 50s?' $(1998,200)$ - this is also a question we need to ask of academic texts, which are as much a product of that 'fame culture' as the stars themselves. Contemporary discourses on fame may well contribute to a culture in which the emphasis is on 'newness' and change - making attempts to probe clear connections with the past somewhat unfashionable. This can apply both to the history of fame, and the history of academic literature in the field (fields which I have suggested are inextricably intertwined). But what might seem to be a somewhat circuitous journey here - suggesting the developments in star/celebrity studies after Dyer, only to find many of his arguments still relevant - is ultimately productive as it demonstrates how, in a field which has always negotiated stark contradictions, it is difficult to assert clear arguments about shift, change and development. The topic of selfhood and identity is particularly important, as it appears to be where popular discourse on contemporary celebrity and academic perspectives meet. While critics in the press are unlikely to be debating the difference between the pre-modern and postmodern self, and the academic arguments here (Lovell, King), are certainly not intending to be dismissive of celebrity, there is an apparent agreement that contemporary celebrity is somewhat depthless, vacuous - palpably different to 'the past'. But the process of ascertaining whether we have witnessed a 'new configuration in the existential parameters of stardom' (King 2003, 45), particularly at a textual level, is enormously difficult. Celebrity sites such as reality TV and heat magazine, seem in many ways traditional and conservative in their construction of celebrity. There is at least as much scope to consider connections with the past here, as there is to follow urgent pointers in the pursuit of the 'new'. That said, the intention here was not to deny change, but to call for a greater self-reflexivity about how we are expanding analysis in the field. Ultimately, the difficulties this seems to pose may well point to King's 
suggestion that, 'the more focused and substantive the study of the topic becomes, the more elusive and "polysemic" the phenomenon appears' (King 1992, 2).

\section{Notes}

1 While the expansion of media outlets may have increased the opportunity for such diverse media engagements with celebrity, this was surely - in principle always a possibility. (Flicking through the pages of Photoplay or Picturegoer in the 1930s was not the same as attending the cinema).

${ }^{2}$ It is important to note here that other approaches have moved the focus away from the celebrity 'image' to particular media 'events' and happenings. Douglas Kellner's Media Spectacle (2003), for example, examines celebrity as one facet of what he terms 'megaspectacles' (e.g. the O.J Simpson trial), in which a multimedia event comes to dominate media culture. Here, Kellner sees the 'megaspectacle' - and not the celebrity per se - as dramatising (while also distracting us from) contemporary social issues.

3 The most famous example of this strategy in the UK version is undoubtedly 'Nasty Nick'. He was ejected from the house by Big Brother for 'cheating' (trying to influence the voting choices of the other contestants).

${ }^{4}$ Jackie Stacey's seminal Stargazing: Hollywood Cinema and Female Spectatorship clearly contributed to empirical audience research in the field, but it drew upon the memories of filmgoers - with all the methodological limitations this may pose.

\section{References}

Babington, B. (2001) (ed.), British Stars and Stardom: From Alma Taylor to Sean Connery, Manchester: Manchester University Press.

Barker, M. (2003) 'Introduction', in T. Austin and M. Barker (eds.), Contemporary Hollywood Stardom, London: Arnold, 2003, pp.1-24.

Becker, K. (1992) 'Photojournalism and the Tabloid Press', in P. Dahlgren and C. Sparks (eds.), Journalism and Popular Culture, London: Sage, pp. 130-152.

Boorstin, D. (1971), The Image: A Guide to Pseudo-Events in America, New York: Atheneum. Originally published as The Image or What Happened to the American Dream? (1961).

Braudy, L. (1986) The Frensy of the Renown; Fame and its History, Oxford: Oxford University Press.

Couldry, N. (2002) 'Playing for Celebrity: Big Brother as Ritual Event', Television and New Media 3 (3): 283-293.

Dyer, R. (1979) (reprinted 1998) Stars. London, BFI. (1986) Heavenly Bodies: Film Stars and Society, London: BFI.

Ellis, J. (1982) Visible Fictions: Cinema, Television, Video, London: Routledge. 
Gamson, J. (1994) Claims to Fame: Celebrity in Contemporary America, Berkeley: University of California Press.

Gamson, J. (2001) 'The Assembly Line of Greatness: Celebrity in TwentiethCentury America', in C. Harrington and D. Bielby (eds.), Popular Culture: Production and Consumption, Oxford: Blackwell, pp. 259-282.

Geraghty, C. (2000) 'Re-examining Stardom: questions of texts, bodies and performance', in C. Gledhill and L. Williams (eds.), Reinventing Film Studies, London: Arnold, pp.183-201.

Hill, A. (2002) 'Big Brother: The real audience', Television and New Media 3 (3) (2002): 323-341.

Holmes, S. (2004a) 'All you've got to worry about is having a cup of tea and doing a bit of sunbathing...': Approaching Celebrity in Big Brother, in S. Holmes and D. Jermyn (eds.), Understanding to Reality TV, London: Routledge, pp. 111-135. (2004b) 'Reality Goes Pop!': Reality TV, Popular Music and Narratives of Stardom in Pop IdoP, Television and New Media 5 (2): 147-172. (2005) "Off guard, Unkempt, Unready?": Deconstructing Contemporary Celebrity in heat Magazine', Continuum: Journal of Media and Cultural Studies 19 (1): 21-38.

(forthcoming, 2006) 'It's a Jungle Out There: The Game of Fame in Celebrity Reality TV', in S. Holmes and S. Redmond (eds.), Framing Celebrity: New Directions in Celebrity Culture, London: Routledge.

Jermyn, D. (forthcoming, 2006) 'Bringing out the * in You: SJP, Carrie Bradshaw and the Evolution of Television Stardom', in S. Holmes and S. Redmond (eds.), Framing Celebrity: New Directions in Celebrity Culture, London: Routledge.

Kear, A. and D. Steinberg (1999) (eds.), Mourning Diana: Nation, Culture and the Performance of Grief, London: Routledge.

Kellner, D. (2003) Media Spectacle, London: Routledge.

King, B. (1992) Stardom and Symbolic Degeneracy: Television and the

Transformation of the Stars as Public Symbols." Semiotica, 92(1-2):1-47. (2003) 'Embodying an Elastic Self: The Parametrics of Contemporary Stardom', in T. Austin and M. Barker (eds.), Contemporary Hollywood Stardom, London: Arnold, pp. 29-44.

Littler, J. (2004) 'Making Fame Ordinary: Intimacy, reflexivity, and 'keeping it real', Mediactive (2): 8-25.

Lovell, A. (2003) 'I Went in Search of Deborah Kerr, Jodie Foster and Julianne Moore but got Waylaid...', in T. Austin and M. Barker (eds.), Contemporary Hollywood Stardom, London: Arnold, pp. 259-270.

Lowenthal, L. (1961) 'The Triumph of Mass Idols', in Lowenthal, Literature, Popular Culture and Society, California: Pacific Books, pp.109-140.

Marshall, P. D. (1997) Celebrity and Power: Fame in Contemporary Culture, Minnesota: University of Minnesota Press. 
(2004) 'Fame's Perpetual Moment', $M / C$ Journal 7.5, available at http://journal.media-culture.org.au/0411/01-editorial.php (accessed 10 November, 2004).

McDonald, P. (1998) 'Reconceptualising Stardom', in Richard Dyer, Stars (second edition), London: BFI, pp. 175-200.

Moran, J. (2000) Star Authors, London: Pluto.

Rojek, C. (2001) Celebrity, London: Reaktion Books.

Sekula, A. (1984) Photography Against the Grain, Halifax, The Press of Nova Scotia College of Art and Design.

Stacey, J. (1994) Stargazing: Hollywood Cinema and Female Spectatorship, London: Routledge.

Stahl, M. (2002) 'Authentic boy bands on TV?: Performers and impresarios in The Monkees and Making the Band', Popular Music 21 (3) (2002): 307-329.

Tasker, Y. and D. Negra (2005) 'In Focus: Postfeminism and Contemporary Media Studies', Cinema Journal 44, Winter: 107-110.

Turner, G, F. Bonner and P. Marshall (2000), Fame Games: The Production of Celebrity in Australia, Cambridge, Cambridge University Press.

Turner, G. (2004) Understanding Celebrity, London: Sage.

Whannel, G. (2001) 'Punishment, redemption and celebration in the popular press: The case of David Beckham', in David L. Andrews and Steven J. Jackson (eds.), Sports Stars, London: Routledge, pp.138-150. 